\title{
Developing a Sustainability Performance Assessment Tool for Public Funded Projects According to Policies and Stakeholders' Perceptions
}

\author{
Yousong Wang, Honglei Yi* and Mian Fang
}

\author{
School of Civil Engineering and Transportation, South China University of Technology, Guangzhou 510640, China
}

\begin{abstract}
Sustainable principles have been applied in many sectors including the construction industry. In light of this requirement, delivery and operation of public funded projects have been given particular attention since they are seen as benchmarks in this industry and possess more significant impact on economy, environment, society, resource utilization, health and safety, as well as project governance. Current studies on assessing sustainability performance of these projects are found to have some gaps. By calculating the sustainability performance indicator, the research reported in this paper introduced an improved System Dynamic model addressing the impact of policies and stakeholders' perceptions based on the previous studies. In addition, the improved model alters the way in which sustainability performance indicator evolves to make it more precise. A real stadium project in Shenzhen, China is presented to illustrate the application of the improved model in appraising the sustainability performance of public funded projects. The case study also reveals the aspects to be enhanced to make the sustainability performance better in this project.
\end{abstract}

Keywords: Policy, public funded projects, stakeholder, sustainability performance indicator, system dynamics.

\section{INTRODUCTION}

The concept of sustainable development and sustainability along with it has become a vital concern and code of conduct for policy makers in all countries. Sustainable development was first brought forward in Stockholm in 1972. As defined in the Bruntland report [1], it is a kind of development which meets the needs of the present generation while not compromising the ability of future generations to meet their own needs. Since then, a number of frameworks of sustainability assessment have been established to evaluate the performance of various objectives. The development of standards by OECD [2] and the indicators established by Krajnc and Glavic [3] formed the foundation of sustainability reporting by covering a standardized set of sustainable indicators for enterprises from all main aspects of sustainable development. In business and management, Peter and $\mathrm{Na}-$ tions [4], Holliday et al. [5] and some other researchers developed different frameworks for sustainability indicators. Azapagic [6] established the sustainable assessment framework for mining and minerals industry, which is compatible to the guidelines made by Global Reporting Initiative [7].

In construction industry, sustainable construction projects have become a flagship for application of sustainable development principles all around the world, especially in developing countries such as China. This is because construction projects are in great and constantly increasing demand to cope with growing economic activity and pressure on limited land [8]. At the same time, construction industry has always been considered one of the main sources of environment pollution and waste generation. Furthermore, construction

*Address correspondence to this author at the School of Civil Engineering and Transportation, South China University of Technology, Guangzhou 510640, China; Tel: +8615920481699; E-mail: yihonglei1122@gmail.com projects are generally long lasting, so the impact of buildings on environment and other aspects is far into the future [9]. Compared to other construction projects, Public Funded Projects (PFPs) play an important role in the construction industry to provide public services through the delivery and implementation of PFPs for the government [10]. This fact is particularly obvious in the development of infrastructure, one typical type of PFPs, in developing countries. Fig. (1) presents the annual public investment of infrastructure projects in developing countries from 1991 to 2011 [11]. Due to the importance of PFPs, improving the sustainability performance of PFPs will set up a benchmark for other projects and have a significant impact on the whole industry in sustainable practices. As a result, producing sustainable PFPs and accurately assessing their sustainability performance provide an effective framework for integrating sustainable development into construction processes and life cycle of buildings; as it could be used as a powerful tool by setting sustainable objectives and priorities, developing appropriate sustainable strategies, and determining performance measures to guide the sustainable decision-making, design, construction, operation and decommissioning processes [12]. What's more, development of PFPs evaluation tools is increasingly necessary in developing countries in order to encourage the construction industry to get into sustainable track [13].

\section{RELATIVE LITERATURE REVIEW AND RE- SEARCH GAP}

\subsection{Sustainable Public Funded Projects}

There are many interpretations of sustainable buildings. Among them, the definition by OECD Project is a widely accepted and quoted one. It defines sustainable buildings as those construction projects which have minimum adverse 


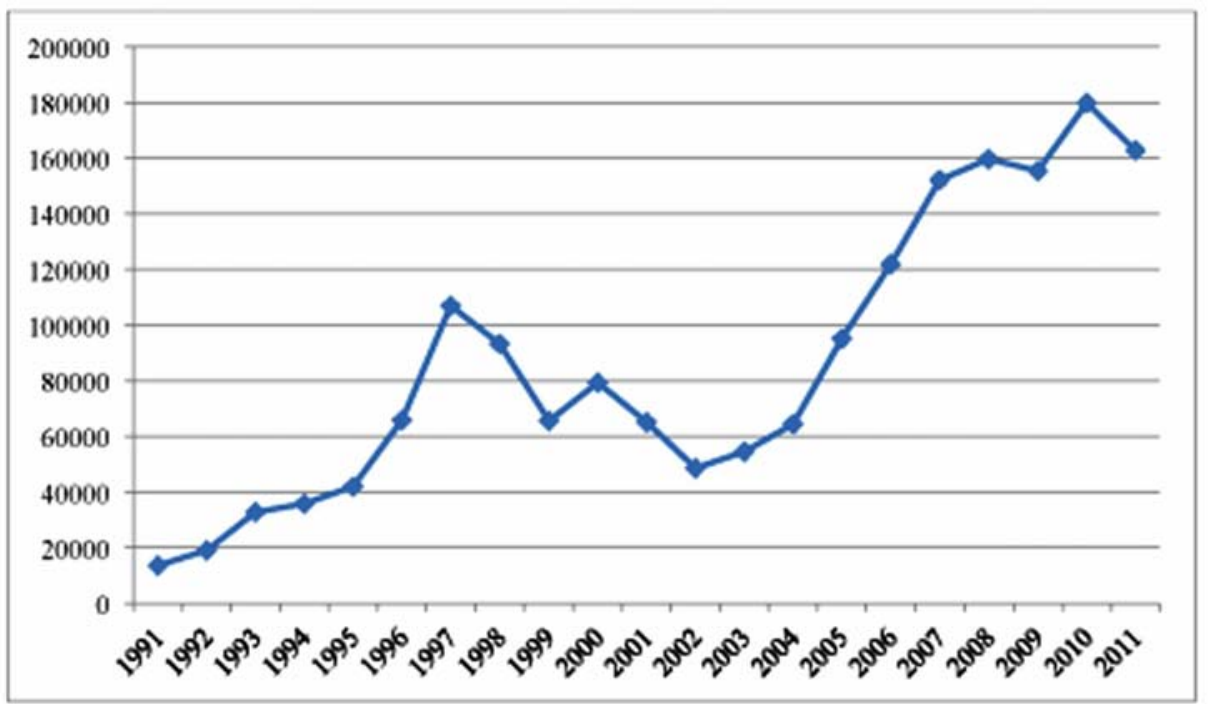

Fig. (1). Annual Public Investment (USD in million) of Infrastructure Projects in Developing Countries between 1991 and 2011.

impacts on the natural and built environment, in terms of the projects themselves, their interacting surroundings, as well as the broader regional and global settings [14]. The OECD project report also identified five targets for sustainable buildings as shown below:

1. Resource efficiency;

2. Energy efficiency (including greenhouse gas emissions reduction);

3. Pollution prevention (including indoor air quality and noise abatement);

4. Harmonization with environment;

5. Integrated and systemic approaches.

On the other hand, Public Funded Projects are greatly desired due to reasons like basic utilities and services, transportation and economic development [15]; yet the practice of PFPs is often criticized for lack of sustainability and considered as a failure [16]. In addition, researchers and practitioners have come to an agreement that PFPs should be decided, constructed, operated and maintained in a sustainable way $[17,18]$. In this light, sustainable Public Funded Projects could be defined as building practices, which provide public services while striving for integral quality in a broad way [19]. The quality stated here includes economic, social, environmental performance, resource utilization, health and safety, as well as project governance [20]. Thus in the whole life cycle of PFPs, the use of natural resources will be rational and management of them be appropriate, which can contribute in reducing energy consumption, saving scarce resources, improving environmental quality, and enhancing positive impacts of the projects on all systems that they interact.

Sustainable Public Funded Projects should take functional quality, environmental quality, and future values into account. The implementation of sustainable PFPs should therefore be the thoughtful integration of architecture with mechanical, electrical, structural engineering and construction management resources. Apart from that, sustainable PFPs need to concern long-term costs including economic, envi- ronmental and human, etc. [19]. With sustainability impacts continuous increase on the lives of individuals, organizations and society at large, the opportunities for holistic and responsible thinking are also increasing. Relative studies reveal four approaches to improve sustainability of PFPs: use of biological and renewable materials, control and elimination of hazardous substances, promotion of resource and energy efficiency, and added functionality in materials and structures $[21,22]$.

\subsection{Sustainability Assessment Methodologies}

Assessment of sustainability performance is the foundation to make the studied objective more sustainable. The existing methodologies regarding this kind of appraisal can be divided into two groups: mainstream economists prefer to adopt monetary aggregation method to address the scarcity value of resources, while researchers and scientists in other disciplines tend to apply physical indicators to present the formation of sustainability [23].

The holistic framework for evaluation of sustainability developed by Ness et al. [24] represents the basic and mainstream thinking in this field. It is based on the time continuum, which allows the tool to overview the past as well as to forecast the future. The framework consists of three modules including (1) indices and indicators, that will be further broken down into integrated and non-integrated; (2) productrelated appraisal tools from a life cycle perspective with the concern on the material and/or energy flows of a product or service; and (3) integrated evaluation, which is a combination of tools to focus on policy change or project implementation.

In assessing sustainability, indicators are necessary. They are related to parameters that can be measured to show trends or sudden changes in a particular condition. The indicators reported in existing literature are developed from two methodological paradigms: one is top-down and expert-led, and the other one is bottom-up and public-based [25]. Normally, indicators are established and used through the following basic steps: identifying human and environmental 
context, setting goals and strategies, evaluating and selecting indicators, and applying indicators to collect data [26].

With indicators identified by the approaches above, there are approximately 600 tools which measure the environmental, social and economic dimensions of sustainability [27]. Similarly, a wide range of sustainable construction projects assessment tools are promoted and readily available in construction industry [28]. The development of the assessment tools commenced in 1990 with the introduction of the first tool Building Research Establishment Environmental Assessment Method (BREEAM) in UK. Five years later, the French system High Environmental Quality (HQE) was established, followed by Leadership in Energy and Environmental Design (LEED) in the States in 2000. The Comprehensive Assessment System for Building Environmental Efficiency (CASBEE) in Japan and Green Star in Australia were developed in 2001 and 2002 respectively [29]. Based on these initial assessment tools and certification systems, many other countries formulated tools of their own, such as LEED in India, GreenStar in South Africa, Building Research Establishment Environmental Assessment Method (BREEAM) in Netherlands, Green Building Assessment System (GBAS) in China and so on.

Among these tools, BREEAM, LEED, Green Star and CASBEE are the most used ones. However, the others are also important, and more suitable regarding various contexts. In fact, the comparison of the tools is difficult, if not impossible. Because they are designed for evaluating different types of buildings, and their emphases of the life cycle phases vary [30]. This fact may imply that there is a need to establish a more holistic method to accurately and quantitatively assess the sustainability performance of construction projects in whole life cycle.

\subsection{Impact of Policies and Stakeholders' Perceptions on Sustainability}

Sustainability performance is obviously affected by the policy system. However, there are many barriers in the development of the system; as the legislations relating to sustainability, climate change and environmental issues are complex, wide ranging and constantly emerging. Hardenbrook [31] reviewed the history and current status of policies on sustainability and resilient infrastructures adopting a regional prospective, and concluded that a policy framework to improve sustainability performance is in great need. In line with his study, there has been a wave of legislations and initiatives introduced at a national and continental level which are directly relevant to the construction and refurbishment of sustainable construction projects, and therefore to the market for sustainable building products.

In 2009, the government of Malaysia decreed the National Green Technology Policy together with a proposed Green Technology Financing Scheme with the value of USD 500 million to promote green and sustainable technologies in construction sector. The reason for this policy is that regulatory change is considered to be a key driver of innovation as local enterprises compete to develop new products that are more efficient, greener and safer [32].

Similarly, EU (European Union) Energy Performance of Buildings Directive commanded member states to set mini- mum requirements on energy performance of buildings, introduce a system of energy performance certification for new and refurbished construction projects, as well as develop plans for low or zero carbon buildings with the public sector leading the way [33]. In UK, the Energy Performance of Buildings Regulations 2008 makes it clear that all new buildings must have an Energy Performance Certificate or Display Energy Certificate, and all new homes must be zero carbon by 2016 [34]. In addition, the Sustainable Development Educational Panel of UK Government set an objective of realizing the inclusion of sustainable development criteria within all course accreditation requirements for the professions and industry lead bodies by 2010 [35].

Policies play a vital role in assisting the construction industry to produce sustainable construction products with intervention and support such as labeling and public information. Apart from this, the sustainability performance of buildings is also dependent on the perceptions of stakeholders. There are several reasons for this. For one thing, sustainability is a perceptual concept in nature; each stakeholder has specific sustainability perception of his own. For another, the implementation and achievement of sustainability will be promoted by the actions of stakeholders [36]. As a result, the perceptions of stakeholders must be taken into account in the research of sustainability of construction projects.

Based on the best practice review, Lu and Cui [37] found that the perception of stakeholders is an important part of sustainability appraisal although their empirical research showed that stakeholders' opinions have not been given due attention. They proposed to put forward an integrated framework with stakeholders' perceptions to meet the sustainability expectations. Likewise, many other studies revealed that, stakeholders' perceptions have a significant impact on the selection of sustainability assessment indicators and the weight of the indicators [26, 38, 39]. Yang [40] and Cole [41] analyzed how to manage and motivate the stakeholders to deliver sustainable products in construction industry. Literatures also point out that the detailed mechanism of the interaction between sustainability and stakeholders' perception needs to be further studied and quantified [40, 42].

\subsection{System Dynamics in Assessing Sustainability Per- formance}

Traditionally, the most frequently used methods for assessing the sustainability performance of buildings include Multi-Attribute Decision Analysis (MADA), Multi-Criteria Decision Making (MCDM), Fuzzy Comprehensive Evaluation (FCE), etc. These methods rely on the opinions of the interviewees a lot and thus are sometimes thought to be subjective. In light of this, recently there are some researches adopting System Dynamics (SD) to objectively assess sustainability of construction projects. Marzouk et al. [43] analyzed the environmental economic, financial, and social influences of building materials and applied SD as one of the decision-making modules to select appropriate materials for pursuing of sustainable construction practices. The research conducted by Kovacic et al. [44] explored to simulate and evaluate sustainable buildings with BIM-supported SD. 
Speaking of studies on this subject, a series of researches of a team consisted of Liyin Shen, Yuzhe Wu, Xiaoling Zhang and others needs to be introduced. In 2005, Shen et al. [45] developed an SD model to simulate the project sustainable performance in terms of sustainability of economic development, social development and environmental development. Following their research, Yao et al. [46] identified suitable indicators for highway infrastructure projects and applied them in the SD model to evaluate the sustainability performance in the construction and operation stage. Afterwards, Zhang et al. [8] further improved the SD model to demonstrate the impacts of technological advancement and changes in people's perceptions on the sustainable development value of construction projects.

The researches mentioned above are significant progress in sustainability assessment for construction projects. They establish an approach to quantitatively assess the sustainability performance of buildings in a relatively objective way, present how the performance changes over time, and simulate the impact of other factors on it. However, there are still some aspects that can be enhanced in them:

1. The dimensions of the sustainability indicators can be expanded to more thoroughly appraise the sustainability performance. In literature 8,45 and 46 , the indicators are selected from social, economic and environmental aspects. Some researchers suggested adding more dimensions [20, 25, 47], and this suggestion is widely accepted [23, 26, 48, 49].

2. The weight of the sustainability indicators can be studied more carefully to reflect the impact of stakeholders' perceptions. In literature 8 , it is assumed that all the stakeholders perceive the importance of indicators in the same way, which may not comply with the facts well [50-53].

3. The method to simulate the evolvement of sustainability performance can be altered to more authentically represent what's happening. In literature 8, 45 and 46, in order to simplify the calculation, the sustainability performance is considered to change at a fixed rate in each stage of the project life cycle. This assumption may not be applicable to each context $[54,55]$.

\section{RESEARCH DESIGN AND DEVELOPMENT}

Inspired by the existing studies, especially by the models established in literature 8, 45 and 46, the research reported in this paper intends to bridge the gaps by developing improved SD model based on previous researches. As a result, the main methodology adopted here is System Dynamics Modeling. SD Modeling is a methodology for understanding and analyzing how complex systems evolve over time. There are three basic foundations in it, which are (1) decision-making, (2) feedback mechanism analysis, and (3) simulation. Decision-making concerns how decision-makers act in the system. Feedback focuses on the generated information to provide insights to decision-makers and affects the decisionmaking process in similar cases in the future. Simulation provides decision-makers with a tool to allow them work in a virtual environment where they can view and analyze the effects of their decisions on the system (Monga 2001).

In effect, SD modeling is among the most popular IT tools to support project management applications in con- struction industry. It is used to deal with dynamic feedbacks of complex projects [56], evaluate project management procedure [57], establish the baseline value of projects [58], etc. There are four elements to be defined and described when adopting SD Modelling methodology: state variables (Stock), flow function (Flow), auxiliary variables (Convertor), and streamline (Connector), along with decision-making feedback loops. These elements are connected to each other to form a system, as presented in (Fig. 2) [8, 45].

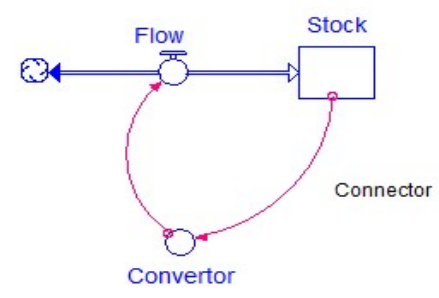

Fig. (2). Basic elements and internal relationships in System Dynamic Modelling.

In Fig. (2), the volume of stock will change due to both in-flows and out-flows over time. Applying this theory in the assessment of construction projects sustainability, different practices and actions by stakeholders can be seen as the flows, which will affect the stock, i.e. performance of sustainability. The relationships between the stock and flow are established as follows:

$$
\operatorname{Stock}(t)=\operatorname{Stock}(t-d t)+(\text { Flow }) d t
$$

Based on the System Dynamic Modeling methodology and its theory, this research was designed and developed as follows:

1. Identify the sub-systems affecting sustainability performance

The authors selected ninety indicators that contribute to the sustainability performance of public funded projects through literature study and questionnaire survey. The detailed process will be reported in another paper. The ninety indicators fall in six dimensions, including economy (EC), society (SO), environment $(\mathrm{EN})$, resource utilization (RU), health and safety (HS), as well as project governance $(\mathrm{PG})$. As a result, this research adopted six attributes to measure the sustainability performance: $E C$, $S O, E N, R U, H S$, and $P G$. In the SD model, they are seen to be the sub-systems. Furthermore, all the attributes are considered to develop in five phases in accordance to life cycle of public funded projects, which consists of stages Decision-making, Design, Construction, Operation, and Demolition.

2. Define the holistic model to assess sustainability performance

In order to quantitatively present the sustainability performance of public funded projects, this research adopted Sustainability Performance Indicator $(S P I)$ in the SD model. SPI is affected by the contribution of the six sustainable attributes, namely, $E C(t), S O(t), E N(t), R U(t)$, $H S(t)$, and $P G(t)$. The relationship is described in Equation (2). 
$S P I(t)=\int_{0}^{t} f(E C(t), S O(t), E N(t), R U(t), H S(t), P G(t)) d t$

As a stock in SD model, SPI increases or decreases as inflows or out-flows occur as the attributes changes. The calculation of SPI was proposed as a weighted value formed by the six dynamic attributes $E C(t), S O(t), E N(t)$, $R U(t), H S(t)$, and $P G(t)$, and the expression of $S P I$ can be written as the following dynamic model:

$$
\left\{\begin{array}{c}
S P I(t)=\int_{0}^{t} W_{E C}(t) I_{E C}(t) d t+\int_{0}^{t} W_{E N}(t) I_{E N}(t) d t+\int_{0}^{t} W_{S O}(t) I_{S O}(t) d t+ \\
\int_{0}^{t} W_{R U}(t) I_{R U}(t) d t+\int_{0}^{t} W_{H S}(t) I_{H S}(t) d t+\int_{0}^{t} W_{P G}(t) I_{P G}(t) d t \\
W_{E C}(t)+W_{E N}(t)+W_{S O}(t)+W_{R U}(t)+W_{H S}(t)+W_{P G}(t)=1
\end{array}\right.
$$

where $I_{E C}(t), I_{S O}(t), I_{E N}(t), I_{R U}(t), I_{H S}(t)$ and $I_{P G}(t)$ denote the dynamic functions of generating economic impact, social impact, environmental impact, resource utilization impact, health and safety impact, and project governance impact from delivering a public funded project. The values of the variables $I_{E C}, I_{S O}, I_{E N}, I_{R U}, I_{H S}$ and $I_{P G}$ are defined as relative measures above -100 , since the policies will not allow a public funded project to perform too bad on sustainability. In addition, the variables $W_{E C}(t)$, $W_{S O}(t), W_{E N}(t), W_{R U}(t), W_{H S}(t)$ and $W_{P G}(t)$ denote the weight of the six sustainable attributes accordingly.

3. Add the impact of policies and perceptions of stakeholders in the system

As discussed earlier, the sustainability performance of public funded projects is also determined by policies and stakeholders' perceptions. Taking this into account, the model needs to be altered by adding the impact of policies and perceptions of stakeholders to incorporate their dynamic effects. By doing this, some new variables were introduced to the model. $E C, S O, E N, R U, S O$ and $P G$ represent $S P I$ from the perspectives of the economy, society, environment, resource utilization, health and safety, and project governance sub-system respectively. The values of these variables are determined by their initial values (ECO, SOO, ENO, RUO, SOO and $P G O)$ and also their adjustment factor ( $A E C, A S O, A E N, A R U, A S O$ and $A P G)$. The final value of $S P I$ for the project as a whole is determined by $E C, S O, E N, R U, S O$ and $P G$.

In terms of the influence of policies, variables of $L A$ and outLA are introduced. $L A$ denotes the changes of the policies on sustainability involving economy, society, environment, resource utilization, health and safety, and project governance aspect. The adjustment factor out $L A$ is a quantitative variable to measure the extent to which $L A$ affects the six sub-systems. When the value of SPI falls below the set limit $L$, some certain action $(L A)$ will need to be taken to improve the $S P I$ value in accordance to requirements of policies. For example, when the project is generating too much waste, relative regulations and policies will force the owner to invest in waste recycling and disposal to reduce the adverse impact. When this dynamic interaction happens, the values of adjustment factors $A E C, A S O, A E N, A R U, A S O$ and $A P G$ change automatically.

For the perceptions of stakeholders, variables of out $W_{E C}$, out $W_{S O}$, out $W_{E N}$, out $W_{R U}$, out $W_{H S}$, and out $W_{P G}$ are defined to denote the weighed importance of the six sustainable sub-systems to different stakeholders. When assessing the perceived sustainability performance of project of dif- ferent stakeholders, the weighting variables $\left(W_{E C}, W_{S O}\right.$, $W_{E N}, W_{R U}, W_{H S}$ and $W_{P G}$ ) change, and thus dimensional sustainability performance values $(E C, S O, E N, R U, S O$ and $P G$ ) and the total sustainability performance value $(S P I)$ are altered accordingly.

4. Determine the way in which dimensional sustainability performance values change

As addressed earlier in this paper, the evolvement of SPI should not be assumed at a fixed rate. In fact, the dimensional sustainability performance values of environment and project governance sub-systems develop constantly. For economic and society sub-systems, the sustainability performance values increase at a certain rate at first, then they become steady for a while, and end up with decreasing. It is similar for health and safety as well as resource utilization sub-systems, despite the values stay in the steady phase until the end of life cycle without declining. The change of SPI can be described by functions. But the detailed development curve of the values needs to be determined based on the specific project and its context.

5. Construction of the System Dynamic model for assessing the sustainability performance

The software used in this research is IThink, which simulates and carries out all the interactions and generation processes in the SD model for assessing sustainability performance of public funded projects. Based on the assumptions and analysis above, the complete model is demonstrated as follows in (Fig. 3).

\section{CASE STUDY}

In order to illustrate the application of the improved System Dynamic model shown in (Fig. 3) and further to validate it, a project located in Shenzhen, China is selected to conduct the case study. The project is a public stadium for leisure and excises in the city. According to the feasibility report, the life cycle of the stadium is 41 years, including the decisionmaking stage ( 2 years), the design stage (1.5 years), the construction stage (5.5 years), the operation stage (30 years), and the demolition stage (2 years). Interviews with experts and involved stakeholders (the government, contractors and public) were conducted to determine the perceived weights of each sustainable attribute of different stakeholders, while collecting the initial values for dimensional sustainability performance. In order to reveal the impacts of stakeholders' perceptions, a set of equally distributed weights was added. The data are listed as in Table 1 and step-functions (4) to (9). In addition, they are input into IThink to make the SD model to operate and visually demonstrate the value distributions. It is worth highlighting that in line with the assumptions in Section 3, the lower limit of SPI is set to be $-100(L=-100)$. When the value of $S P I$ is lower than this, relative policies will take effect to increase it by $1 / 3$, which means $L A$ is considered to be $1 / 3$.

$$
\operatorname{EC} 0(t)=\left\{\begin{array}{cc}
-10 & t \in(0,2] \\
-20 & t \in(2,3.5] \\
-90 & t \in(3.5,9] \\
35(t-9) \quad t \in(9,11] & t \in(11,34] \\
70 \quad t \in & 14(t-34) t \in(34,39] \\
70-10 \quad t \in(39,41]
\end{array}\right.
$$




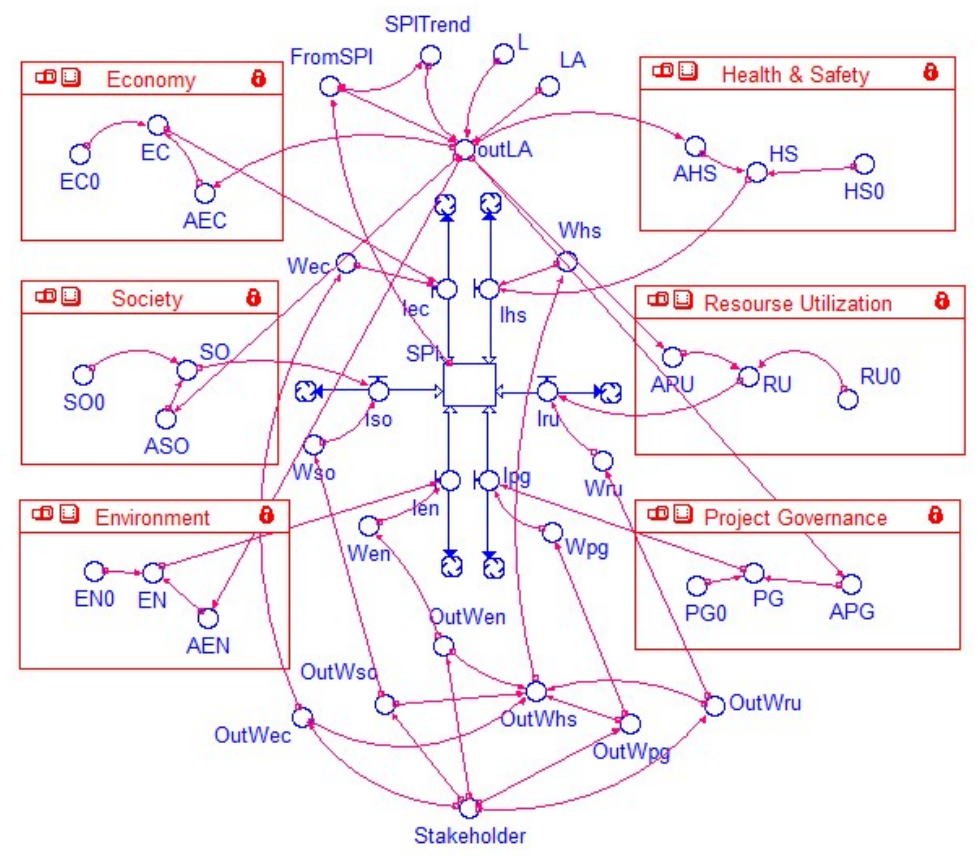

Fig. (3). Improved System Dynamic model for SPI.

Table 1. The weights used in the case study.

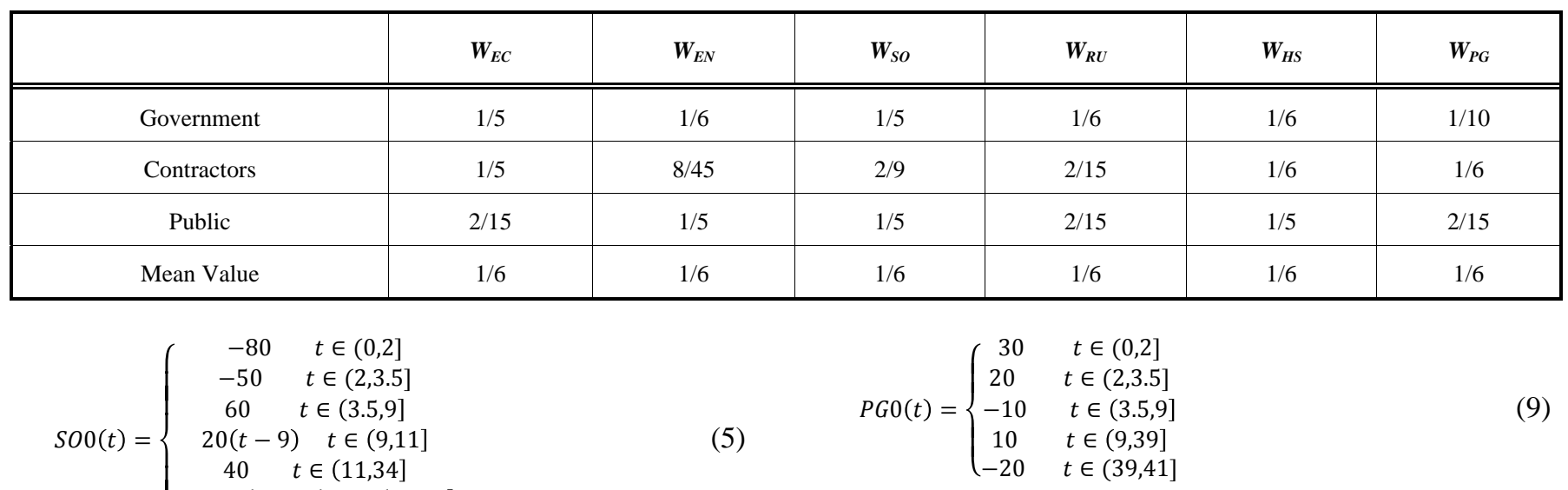

\section{RESULTS AND DISCUSSION}

Running the software, the simulation results of the SPI $\operatorname{EN} 0(t)=\left\{\begin{array}{cc}-60 & t \in(0,2] \\ -40 & t \in(2,3.5] \\ -100 & t \in(3.5,9] \\ 10 & t \in(9,39] \\ -80 & t \in(39,41]\end{array}\right.$ $R U 0(t)=\left\{\begin{array}{cc}-20 & t \in(0,2] \\ -10 & t \in(2,3.5] \\ -60 & t \in(3.5,9] \\ 30 & t \in(9,19]\end{array}\right.$
$30-1.5(t-19) t \in(19,39]$
$-10 \quad t \in(39,41]$
$H S O(t)=\left\{\begin{array}{cc}-10 & t \in(0,2] \\ -30 & t \in(2,3.5] \\ -70 & t \in(3.5,9] \\ 20 & t \in(9,19] \\ 20-(t-19) & t \in(19,39] \\ -20 & t \in(39,41]\end{array}\right.$ values are presented in (Table $\mathbf{2}$ and Fig. 4) in ways of numbers and curves. The procedures undertaken by the simulation model for assessing sustainability performance of the projects adopting System Dynamics are provided in Appen$\operatorname{dix}$ A.

Although the detailed values are different, the four curves in (Fig. 4) evolve in the same trend. They constantly go down in the beginning until the construction of the project finishes. After that, SPI keeps increasing during the operation stage. Through the demolition stage, SPI declines again. It indicates that practices involved in decision-making, design, construction and demolition stage negatively contribute to the sustainability performance of the project. This is easy to understand since in these stages of a project, actions including expropriating the land, largely consuming resource 
Table 2. The simulation results of SPI for the studied project.

\begin{tabular}{|c|c|c|c|c|}
\hline 1 & 0 & 0 & 0 & 0 \\
\hline 3 & -56.5 & -53.81 & -56.5 & -47.5 \\
\hline 4 & -86.83 & -81 & -86.33 & -75 \\
\hline 6 & -142.83 & -126.33 & -139.33 & -137.92 \\
\hline 7 & -165.06 & -143.52 & -160.22 & -161.25 \\
\hline 8 & -187.28 & -160.7 & -181.11 & -184.58 \\
\hline 9 & -209.5 & -177.89 & -202 & -207.92 \\
\hline 13 & -106.43 & -78.67 & -110.97 & -113.23 \\
\hline 14 & -73.43 & -46.34 & -82.31 & -83.23 \\
\hline 15 & -40.43 & -14.01 & -53.64 & -53.23 \\
\hline 16 & -7.43 & 18.33 & -24.97 & -23.23 \\
\hline 17 & 25.57 & 50.66 & 3.69 & 6.77 \\
\hline 18 & 58.57 & 82.99 & 32.36 & 36.77 \\
\hline 19 & 91.57 & 115.33 & 61.03 & 66.77 \\
\hline 20 & 124.41 & 147.55 & 89.54 & 96.61 \\
\hline 26 & 312.73 & 334.57 & 252.24 & 266.93 \\
\hline 27 & 342.65 & 364.69 & 277.96 & 293.85 \\
\hline 28 & 372.16 & 394.51 & 303.28 & 320.36 \\
\hline 29 & 401.26 & 424.04 & 328.19 & 346.46 \\
\hline 30 & 429.93 & 453.26 & 352.71 & 372.14 \\
\hline 31 & 458.19 & 482.18 & 376.83 & 397.4 \\
\hline 32 & 486.04 & 510.8 & 400.54 & 422.24 \\
\hline 33 & 513.47 & 539.12 & 423.86 & 446.67 \\
\hline 34 & 540.48 & 567.14 & 446.78 & 470.68 \\
\hline 35 & 565.42 & 593.14 & 468 & 492.9 \\
\hline 36 & 585.55 & 614.27 & 485.35 & 511.03 \\
\hline 37 & 600.86 & 630.52 & 498.83 & 525.08 \\
\hline 38 & 611.35 & 641.89 & 508.45 & 535.05 \\
\hline 39 & 617.03 & 648.38 & 514.2 & 540.94 \\
\hline 40 & 596.45 & 627.08 & 491.53 & 520.52 \\
\hline 41 & 568.11 & 597.52 & 460.2 & 492.19 \\
\hline
\end{tabular}




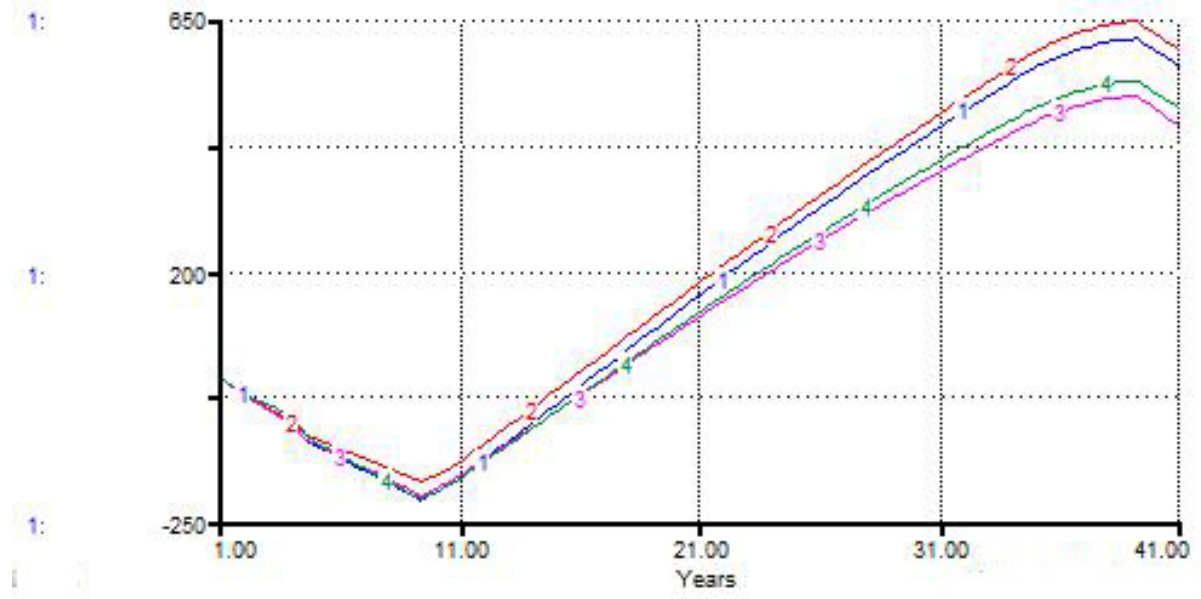

Fig. (4). The simulation results of SPI for the studied project.

and energy, generating various kinds of waste, etc. take place. On the other hand, SPI steadily mounts up in the process of operating because the harmonization between and inside the six sub-systems is relatively easy to gain. This trend of the curves also coincides with existing researches and our common sense.

Curve 1 in Fig. (4) represents the perceived SPI value of the Government in this specific project, while curves 2 and 3 represent that of the contractors and public respectively. Curve 4 is a marker. It is simulated when the weights of the six sustainable attributes are equally 1/6. The differences between the four curves are due to the variation of the weights, which are determined by the perceptions of the stakeholders. This indicates the significant impact of preferences of stakeholders.

It can be seen from the figure that curves 1 and 2 are quite near to each other. This reveals that the perceptions of the government and contractors are more similar compared to that of the public. Government and contractors value aspects of economy and project governance more than the public, while the public intends to address the aspects of health and safety as well as environment more than they do. The curve of the public is not distant to the marker curve 4 . This means the perceived importance of economy, environment, society, resource utilization, health and safety, and project governance is distributed more equably.

At the end of the life cycle of the studied project, the SPI of government, contractors and the public is 568.11, 597.52 and 460.2 respectively. This indicates that this project is considered to be sustainable by the three kinds of stakeholders. But the extent of the sustainability is perceived higher by government and contractors, because the project makes better contribution to the economy, society and project governance sub-systems than to environment and health and safety, which is considered more important by the public. This implies that it needs to take the sustainability performance of environment and health and safety into account more to satisfy the public.

It is worth noting that the values of the parameters in this simulation, including $W_{E C}, W_{S O}, W_{E N}, W_{R U}, W_{H S}, W_{P G}, L$ and
$L A$ are collected in the specific context of this project. They will vary in accordance to project nature, client requirements and stakeholders interviewed. But the results discussed above reveal the trend of the distribution and evolvement of SPI. This can be useful to other researchers.

\section{CONCLUSION}

After reviewing the previous studies in assessment of sustainability performance of public funded projects, this research proved System Dynamic Modeling is a suitable and useful research tool in this field. However, research gaps were also identified in the dimensions of sustainable attributes, weights of these attributes and the way sustainability performance evolves. Based on the existing literatures, this study altered the SD model to develop an improved SD model for assessing the sustainability performance of public funded projects, with considerations of policies and perceptions of different stakeholders. A real project in Shenzhen, China was employed as a studied case to demonstrate the application of the improved model. The case study also revealed the development and change of the sustainability performance due to the impact of policies and stakeholders' perceptions.

There are several limitations of this study. First, the established model does not distinguish the change of the perceptions of stakeholders over time. As a matter of fact, the six dimensions should have varied perceived importance for a certain stakeholder. Second, the data used in the case study was collected by surveys with the stakeholders and experts. This method may be considered subjective. Future research can be conducted to manage these challenges.

\section{CONFLICT OF INTEREST}

The authors confirm that this article content has no conflicts of interest.

\section{ACKNOWLEDGEMENTS}

Declared none. 


\section{APPENDIX A}

The formula to simulate the Improved SD model for SPI in software IThink

$$
\begin{aligned}
& \text { AEC }=\text { outLA } \\
& \text { EC }=\text { EC0 } *(1+E C 0 / A B S(E C 0) * A E C) \\
& \text { EC0 }=\text { IF(TIME<=2) THEN(-10) ELSE(IF(TIME<=3.5) } \\
& \text { THEN(-20) ELSE(IF(TIME<=9) THEN(-90) } \\
& \text { ELSE(IF(TIME<=11) THEN(0.0001+RAMP(35,9)) } \\
& \text { ELSE(IF(TIME<=34) THEN(70) ELSE(IF(TIME<=39) } \\
& \text { THEN(70.0001+RAMP(-14,34)) ELSE }(-10)))))
\end{aligned}
$$

$$
\begin{aligned}
& \mathrm{AEN}=\text { outLA } \\
& \mathrm{EN}=\mathrm{EN} 0 *(1+\mathrm{EN} 0 / \mathrm{ABS}(\mathrm{EN} 0) * \mathrm{AEN}) \\
& \text { EN0 }=\text { IF }(\text { TIME }<=2) \text { THEN }(-60) \text { ELSE(IF(TIME }<=3.5) \\
& \text { THEN(-40) ELSE(IF(TIME }<=9) \text { THEN }(-100) \\
& \text { ELSE(IF(TIME<=39) THEN(10) ELSE(-80)))) } \\
& \text { AHS }=\text { outLA } \\
& \mathrm{HS}=\mathrm{HSO}^{*}\left(1+\mathrm{HSO} / \mathrm{ABS}(\mathrm{HS} 0)^{*} \mathrm{AHS}\right) \\
& \text { HS0 }=\operatorname{IF}(\text { TIME }<=2) \text { THEN }(-10) \text { ELSE }(\operatorname{IF}(\text { TIME }<=3.5) \\
& \text { THEN(-30) ELSE(IF(TIME<=9) THEN(-70) } \\
& \text { ELSE(IF(TIME }<=19) \text { THEN(20) ELSE(IF(TIME }<=39) \\
& \operatorname{THEN}(20.0001+\operatorname{RAMP}(-1,19)) \operatorname{ELSE}(-20))))) \\
& \mathrm{APG}=\text { outLA } \\
& \mathrm{PG}=\mathrm{PG} 0 *(1+\mathrm{PG} 0 / \mathrm{ABS}(\mathrm{PG} 0) * \mathrm{APG}) \\
& \text { PG0 }=\operatorname{IF}(\text { TIME }<=2) \text { THEN }(30) \text { ELSE(IF(TIME }<=3.5) \\
& \text { THEN(20) ELSE(IF(TIME<=9) THEN(-10) } \\
& \text { ELSE(IF(TIME<=39) THEN(10) ELSE(-20)))) } \\
& \text { ARU = outLA } \\
& \mathrm{RU}=\mathrm{RU} 0 *(1+\mathrm{RU} 0 / \mathrm{ABS}(\mathrm{RU} 0) * \mathrm{ARU}) \\
& \text { RU0 }=\operatorname{IF}(\text { TIME }<=2) \text { THEN }(-20) \text { ELSE }(\operatorname{IF}(\text { TIME }<=3.5) \\
& \text { THEN(-10) ELSE(IF(TIME<=9) THEN(-60) } \\
& \text { ELSE(IF(TIME <=19) THEN(30) ELSE(IF(TIME<=39) } \\
& \text { THEN(30.0001+RAMP(-1.5,19)) ELSE(-10))))) } \\
& \mathrm{ASO}=\text { outLA } \\
& \mathrm{SO}=\mathrm{SO} 0 *(1+\mathrm{SO} 0 / \mathrm{ABS}(\mathrm{SO} 0) * \mathrm{ASO}) \\
& \text { SO0 }=\operatorname{IF}(\text { TIME }<=2) \text { THEN }(-80) \text { ELSE }(\operatorname{IF}(\text { TIME }<=3.5) \\
& \text { THEN(-50) ELSE(IF(TIME }<=9) \text { THEN(60) } \\
& \text { ELSE(IF(TIME< }<11) \text { THEN }(0.0001+\operatorname{RAMP}(20,9)) \\
& \text { ELSE(IF(TIME<=34) THEN(40) ELSE(IF(TIME<=39) } \\
& \operatorname{THEN}(40.0001+\operatorname{RAMP}(-8,34)) \text { ELSE(-30)))))) }
\end{aligned}
$$

Not in a sector $\mathrm{dt}$$$
\operatorname{SPI}(\mathrm{t})=\operatorname{SPI}(\mathrm{t}-\mathrm{dt})+(\mathrm{Iec}+\mathrm{Iso}+\mathrm{Ien}+\mathrm{Ihs}+\mathrm{Iru}+\mathrm{Ipg}) *
$$

$$
\text { INIT SPI }=0
$$

INFLOWS:

$$
\begin{aligned}
& \text { Iec }=\mathrm{EC} * \mathrm{Wec} \\
& \text { Iso }=\mathrm{SO} * \mathrm{Wso} \\
& \text { Ien }=\mathrm{EN} * \mathrm{Wen} \\
& \text { Ihs }=\mathrm{HS} * \mathrm{Whs} \\
& \text { Iru }=\mathrm{RU} * \mathrm{Wru}
\end{aligned}
$$

$\mathrm{Ipg}=\mathrm{PG} * \mathrm{Wpg}$

FromSPI $=$ SPI

$\mathrm{L}=-100$

$\mathrm{LA}=1 / 3$

outLA $=\operatorname{IF}($ SPITrend $=0$ AND $($ FromSPI $<$ L $))$ THEN $($ LA $)$ $\operatorname{ELSE}(0)$

OutWec $=$ IF $($ Stakeholder $=1)$ THEN $(1 / 5)$

ELSE(IF(Stakeholder=2) THEN(1/5)

ELSE(IF(Stakeholder=3) THEN(2/15) ELSE(1/6)))

OutWen $=\operatorname{IF}($ Stakeholder $=1)$ THEN $(1 / 6)$

ELSE(IF(Stakeholder=2) THEN(8/45)

ELSE(IF(Stakeholder=3) THEN(1/5) ELSE(1/6)))

OutWhs $=1$-OutWec-OutWen-OutWpg-OutWruOutWso

OutWpg $=\mathrm{IF}($ Stakeholder=1) $\mathrm{THEN}(1 / 10)$

ELSE(IF(Stakeholder=2) THEN(1/6)

ELSE(IF(Stakeholder=3) THEN(2/15) ELSE(1/6)))

OutWru = IF(Stakeholder $=1)$ THEN $(1 / 6)$

ELSE(IF(Stakeholder=2) THEN(2/15)

ELSE(IF(Stakeholder=3) THEN(2/15) ELSE(1/6)))

OutWso $=$ IF $($ Stakeholder $=1)$ THEN $(1 / 5)$

ELSE(IF(Stakeholder=2) THEN(2/9)

ELSE(IF(Stakeholder=3) THEN(1/5) ELSE(1/6)))

SPITrend $=$ SWITCH $($ FromSPI,DELAY $($ FromSPI,1 $))$

Stakeholder $=1$

Wec $=$ OutWec

Wen $=$ OutWen

Whs $=$ OutWhs

$\mathrm{Wpg}=$ OutWpg

$\mathrm{Wru}=$ OutWru

$\mathrm{Wso}=$ OutWso

\section{REFERENCES}

[1] G. Bruntland, "Our common future: The world commission on environment and development", ed: Oxford: Oxford University Press, 1987.

[2] OECD, "Towards Sustainable Development: Environmental Indicators," Paris 1998.

[3] D. Krajnc and P. Glavič, "A model for integrated assessment of sustainable development", Resources, Conservation and Recycling, vol. 43, pp. 189-208, 2005.

[4] P. Utting and N. Unies, Business responsibility for sustainable development vol. 2: United Nations Research Institute for Social Development Geneva, 2000.

[5] C. O. Holliday Jr, S. Schmidheiny, and P. Watts, Walking the talk: The business case for sustainable development: Berrett-Koehler Publishers, 2002.

[6] A. Azapagic, "Developing a framework for sustainable development indicators for the mining and minerals industry", Journal of cleaner production, vol. 12, pp. 639-662, 2004.

[7] G. R. Initiative, Sustainability Reporting Guidelines: on Economic, Environmental, and Social Performance: Global Reporting Initiative, 2000.

[8] X. Zhang, Y. Wu, L. Shen, and M. Skitmore, "A prototype system dynamic model for assessing the sustainability of construction projects", International Journal of Project Management, vol. 32, no 1, pp. 66-76, 2013. 
[9] W. Fawcett, M. Hughes, H. Krieg, S. Albrecht, and A. Vennström, "Flexible strategies for long-term sustainability under uncertainty", Building Research \& Information, vol. 40, pp. 545-557, 2012/10/01 2012.

[10] H. Yi and Y. Wang, "Trend of the research on public funded projects", Open Construction and Building Technology Journal, vol. 7, pp. 51-62, 2013.

[11] WorldBank, "Private Participation in Infrastructure Database", ed. 2013.

[12] H. H. Ali and S. F. Al Nsairat, "Developing a green building assessment tool for developing countries - Case of Jordan", Building and Environment, vol. 44, pp. 1053-1064, 2009.

[13] A. Libovich, "Assessing green building for sustainable cities", in Proceedings of the world sustainable building conference. Tokyo, 2005, pp. 1968-71.

[14] OECD, "Design of sustainable building policies," Paris 2002.

[15] C. Ebdon and P. Landow, "The balancing act: Using private money for public projects," Public Budgeting \& Finance, vol. 32, pp. 5879, 2012.

[16] K. Samset, Project evaluation: making investments succeed: Tapir Forlag, 2003.

[17] W.C. Baum and S.M. Tolbert, Investing in development: Lessons of World Bank Experience: Cambridge Univ Press, 1985.

[18] F. Emuze and J.J. Smallwood, "Bridging public works project performance gaps in South Africa," Proceedings of the ICEManagement, Procurement and Law, vol. 165, pp. 111-118, 2012.

[19] G. John, D. Clements-Croome, and G. Jeronimidis, "Sustainable building solutions: a review of lessons from the natural world", Building and Environment, vol. 40, pp. 319-328, 2005.

[20] O. O. Ugwu and T. C. Haupt, "Key performance indicators and assessment methods for infrastructure sustainability-a South African construction industry perspective", Building and Environment, vol. 42, pp. 665-680, 2007.

[21] W. McDonough and M. Braungart, "Towards a sustaining architecture for the 21st century: the promise of cradle-to-cradle design", Industry and Environment, vol. 26, pp. 13-16, 2003.

[22] D.C. Croome, Intelligent buildings: design, management and operation: Thomas Telford, 2004.

[23] R.K. Singh, H.R. Murty, S.K. Gupta, and A.K. Dikshit, "An overview of sustainability assessment methodologies", Ecological Indicators, vol. 9, pp. 189-212, 2009.

[24] B. Ness, E. Urbel-Piirsalu, S. Anderberg, and L. Olsson, "Categorising tools for sustainability assessment", Ecological Economics, vol. 60 , pp. 498-508, 2007.

[25] S. Bell and S. Morse, "Breaking through the Glass Ceiling: who really cares about sustainability indicators?", Local Environment, vol. 6, pp. 291-309, 2001.

[26] M.S. Reed, E.D.G. Fraser, and A.J. Dougill, "An adaptive learning process for developing and applying sustainability indicators with local communities", Ecological Economics, vol. 59, pp. 406-418, 2006.

[27] J. Walton, M. El-Haram, N. Castillo, R. Horner, A. Price, and C. Hardcastle, "Integrated assessment of urban sustainability", Proceedings of the ICE-Engineering Sustainability, vol. 158, pp. 5765, 2005.

[28] R. Reed, S. Wilkinson, A. Bilos, and K.-W. Schulte, "A comparison of international sustainable building tools-An update," in The 17th Annual Pacific Rim Real Estate Society Conference, Gold Coast, 2011, pp. 16-19.

[29] G. Debizet and M. Symes, "Expertise and methodology in building design for sustainable development", Sustainable Urban Development Volume 4 Changing Professional Practice, pp. 197-228, 2008.

[30] A. Haapio and P. Viitaniemi, "A critical review of building environmental assessment tools", Environmental Impact Assessment Review, vol. 28, pp. 469-482, 2008.

[31] B.J. Hardenbrook, "The need for a policy framework to develop disaster resilient regions", Journal of Homeland Security and Emergency Management, vol. 2, 2005.

[32] L.B. Tik, S.L. Tatt, and T.M. Chuan, "Sustainable Construction in Malaysia: A Consultants' Perspective".

[33] O. Ortiz, F. Castells, and G. Sonnemann, "Sustainability in the construction industry: A review of recent developments based on
LCA", Construction and Building Materials, vol. 23, pp. 28-39, 2009.

[34] EU. (2009). Scoping study into future market opportunities for sustainable building products Available: http://europa.eu/index_en.htm

[35] T.M. Korman and N. Lu, "Review of current legislation, codes, and certifications increasing the sustainability standards for construction operations", in ICSDC 2011, Ed. pp. 129-135.

[36] H. Smyth, "The credibility gap in stakeholder management: Ethics and evidence of relationship management", Construction Management and Economics, vol. 26, pp. 633-643, 2008.

[37] Q. Cui and Y. Lu, "Sustainability rating system for construction corporations: A best practice review," in ICSDC 2011, ed, pp. 151160.

[38] S. u. R. Toor and S.O. Ogunlana, "Beyond the 'iron triangle': Stakeholder perception of key performance indicators (KPIs) for large-scale public sector development projects", International Journal of Project Management, vol. 28, pp. 228-236, 2010.

[39] R.K. Larsen, E. Calgaro, and F. Thomalla, "Governing resilience building in Thailand's tourism-dependent coastal communities: Conceptualising stakeholder agency in social-ecological systems", Global Environmental Change, vol. 21, pp. 481-491, 2011.

[40] J. Yang, "A framework for stakeholder management in construction projects", Ph.D. 3448517, Hong Kong Polytechnic University (Hong Kong), Hong Kong, 2010.

[41] R.J. Cole, "Motivating stakeholders to deliver environmental change", Building Research \& Information, vol. 39, pp. 431-435, 2011/10/01 2011.

[42] K. Moodley, N. Smith, and C.N. Preece, "Stakeholder matrix for ethical relationships in the construction industry", Construction Management and Economics, vol. 26, pp. 625-632, 2008.

[43] M.T. Elsheikh, M.M. Marzouk, and M.S. Abdelhamid, "Selecting building materials using system dynamics and ant colony optimization," in ICSDC 2011, Ed. pp. 577-584.

[44] I. Kovacic, L. Oberwinter, and C. Müller, "CIB 2013 World Congress BIM-supported planning process for sustainable buildingsProcess simulation and evaluation through exploratory research".

[45] L. Shen, Y. Wu, E. Chan, and J. Hao, "Application of system dynamics for assessment of sustainable performance of construction projects", Journal of Zhejiang University Science A, vol. 6, pp. 339-349, 2005

[46] H. Yao, L. Shen, Y. Tan, and J. Hao, "Simulating the impacts of policy scenarios on the sustainability performance of infrastructure projects", Automation in Construction, vol. 20, pp. 1060-1069, 2011.

[47] G. Fernández-Sánchez and F. Rodríguez-López, "A methodology to identify sustainability indicators in construction project management-Application to infrastructure projects in Spain", Ecological Indicators, vol. 10, pp. 1193-1201, 2010.

[48] M. Sohail and A. N. Baldwin, "Performance indicators for 'microprojects' in developing countries", Construction Management and Economics, vol. 22, pp. 11-23, 2004.

[49] A. Milman and A. Short, "Incorporating resilience into sustainability indicators: An example for the urban water sector", Global Environmental Change, vol. 18, pp. 758-767, 2008.

[50] R. Garvare and P. Johansson, "Management for sustainability-a stakeholder theory", Total Quality Management, vol. 21, pp. 737744, 2010.

[51] A. Kolk and J. Pinkse, "Towards strategic stakeholder management? Integrating perspectives on sustainability challenges such as corporate responses to climate change", Corporate Governance, vol. 7, pp. 370-378, 2007.

[52] B. Kasemir, Public participation in sustainability science: a handbook: Cambridge University Press, 2003.

[53] V. N. Mathur, A. D. Price, and S. Austin, "Conceptualizing stakeholder engagement in the context of sustainability and its assessment", Construction Management and Economics, vol. 26, pp. 601609, 2008.

[54] S. N. F. Leong, "Sustainability: driver for decision making in infrastructure," 2010.

[55] O.J. Klakegg and T. Haavaldsen, "Governance of major public investment projects: in pursuit of relevance and sustainability", International Journal of Managing Projects in Business, vol. 4, pp. 157-167, 2010. 
[56] P. Love, G. Holt, L. Shen, H. Li and Z. Irani, "Using systems dynamics to better understand change and rework in construction project management systems", International Journal of Project Management, vol. 20, pp. 425-436, 2002.

[57] S. Chritamara, S. Ogunlana, and N. Bach, "System dynamics modeling of design and build construction projects", Construction In- novation: Information, Process, Management, vol. 2, pp. 269-295, 2002.

[58] K. D. Hemanta and J. Ali, "Toward a dynamic simulation model for strategic decision-making in life-cycle project management", Project Management Journal, vol. 33, p. 23, 2002.

(C) Wang et al.; Licensee Bentham Open.

This is an open access article licensed under the terms of the Creative Commons Attribution Non-Commercial License (http://creativecommons.org/licenses/by-nc/3.0/) which permits unrestricted, non-commercial use, distribution and reproduction in any medium, provided the work is properly cited. 